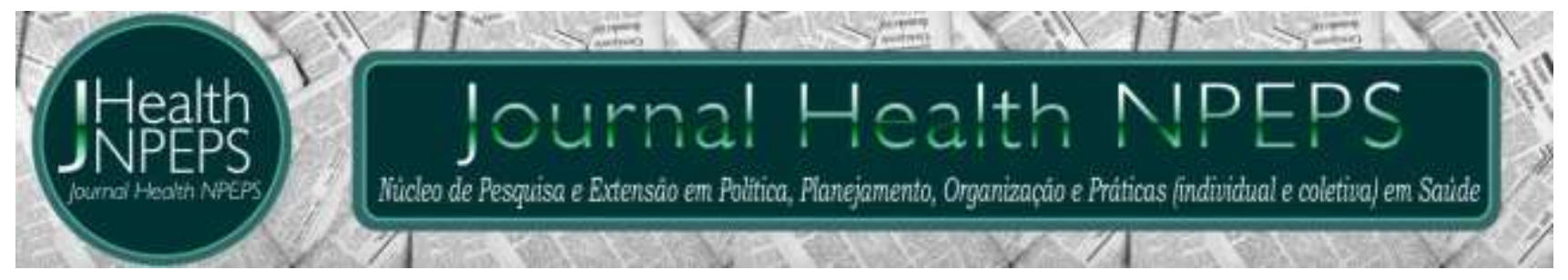

http://dx.doi.org/10.30681/252610103362

ARTIGO ORIGINAL

\title{
Capacitação multiprofissional sobre drogas no contexto escolar: formação, saúde e educação
}
Multiprofessional training on drugs in the school context: training, health and education
Capacitación multiprofesional sobre drogas en el contexto escolar: formación, salud y educación

\section{Pâmela Migliorini Claudino da Silva1, Tanyse Galon², Adaene Alves Machado de Moura $^{3}$, Rosa Jacinto Volpato ${ }^{4}$, Sonia Regina Zerbetto ${ }^{5}$, Angelica Martins de Souza Gonçalves ${ }^{6}$}

\section{RESUMO}

Objetivo: elaborar uma capacitação sobre uso de substâncias psicoativas destinada a professores de ensino médio e fundamental e submetê-lo à avaliação por especialistas. Método: foi realizado um estudo metodológico e qualitativo. A trajetória metodológica seguiu as etapas: desenvolvimento de aulas da capacitação, envio do material para análise das especialistas e avaliação das questões. Resultados: foram avaliados 11 itens do questionário avaliativo de conformidade, e apenas dois deles não apresentaram concordância. Na análise qualitativa, foram produzidas quatro categorias temáticas: construir estratégias em parceria, contextualizar o tema, quebrar paradigmas e produzir reflexão, e promover conhecimentos específicos. O modelo proposto foi capaz de instrumentalizar os professores na identificação dos padrões do uso de drogas.

\footnotetext{
${ }^{1}$ Assistente Social. Mestra em Ciências da Saúde. Atua na unidade de emergência do Hospital das Clínicas da Faculdade de Medicina de Ribeirão Preto - UE-HC/FMRP-USP. Ribeirão Preto, SP, Brasil. E-mail: pamelamigliorini@yahoo.com.br ORCID ID: https://orcid.org/0000-0003-1662-5067

${ }^{2}$ Enfermeira. Doutora em Ciências. Docente Adjunta da Universidade Federal do Triângulo Mineiro - UFTM. Uberaba, MG, Brasil. E-mail: tanyse.galon@ufmt.edu.br ORCID ID:https://orcid.org/0000-0001-6407-5739

${ }^{3}$ Enfermeira. Mestra em Ciências da Saúde. Doutoranda em Ciências no Programa de Pós-graduação em Enfermagem Psiquiátrica da Universidade de São Paulo (EERP-USP). Ribeirão Preto, SP, Brasil. E-mail: adaene moura@usp.br ORCID ID: https://orcid.org/0000-0001-7607-9841

${ }^{4}$ Enfermeira. Mestra em Ciências da Saúde. Programa de Pós-graduação em Enfermagem da Universidade Federal de São Carlos, São Carlos, SP, Brasil. E-mail: rosamjacinto@hotmail.com ORCID ID: https://orcid.org/0000-0001-5709$\underline{7008}$

${ }^{5}$ Enfermeira. Doutora em Enfermagem Psiquiátrica. Docente Associado da Universidade Federal de São Carlos (UFSCar). São Carlos, SP, Brasil. E-mail: szerbetto@hotmail.com ORCID ID: https://orcid.org/0000-0002-2522-1948

${ }^{6}$ Enfermeira. Doutora em Ciências. Docente Adjunta da Universidade Federal de São Carlos (UFSCar). São Carlos, SP, Brasil. E-mail: angelicamartins@ufscar.br ORCID ID: https://orcid.org/0000-0002-7265-5837 Autor principal Endereço para correspondência: Rod. Washington Luiz, s/n, São Carlos - SP, CEP: 13565-905.
}

Este artigo está licenciado sob forma de uma licença Creative Commons Atribuição 4.0 Internacional, que permite uso irrestrito, distribuição e reprodução em qualquer meio, desde que a publicação original seja corretamente citada. 
Considerações finais: avaliação de especialistas na área da saúde, se constitui como uma etapa fundamental na busca por maior sucesso na oferta de capacitações desta natureza. Materiais destinados à capacitação de professores, além do aspecto técnico, devem prezar pela diversidade contextual de atuação docente. Descritores: Capacitação em Serviço; Educação; Pesquisa Qualitativa; Docentes; Serviços de Saúde Escolar.

\begin{abstract}
Objective: to develop a training on the use of psychoactive substances for secondary and elementary school teachers and to subject it to expert evaluation. Method: a qualitative and methodological study was carried out. The methodological trajectory followed the steps: development of training classes, submission of material for the analysis of experts and evaluation of issues. Results: eleven items of the conformity assessment questionnaire were evaluated, and only two of them showed no agreement. In the qualitative analysis, four thematic categories were produced: building strategies in partnership, contextualize the theme, breaking paradigms and producing reflection, and promote specific knowledge. The proposed model was able to instrumentalize teachers in identifying patterns of drug use. Final considerations: evaluation of health experts is a fundamental step in the search for greater success in the provision of training of this nature. Materials for the training of teachers, besides the technical aspect, should value the contextual diversity of teaching performance.

Descriptors: Service Training; Education; Qualitative Research; Teachers; School Health Services.
\end{abstract}

\title{
RESUMEN
}

Objetivo: elaborar una capacitación sobre uso de sustancias psicoactivas destinada a profesores de enseñanza media y fundamental y someterlo a la evaluación por especialistas. Método: se realizó un estudio metodológico y cualitativo. La trayectoria metodológica siguió las etapas: desarrollo de clases de la capacitación, el envío del material para el análisis de los expertos y la evaluación de las cuestiones. Resultados: fueron evaluados 11 ítems del cuestionario evaluador de conformidad, y sólo dos de ellos no presentaron concordancia. En el análisis cualitativo, se produjeron cuatro categorías temáticas: construir estrategias en asociación; contextualizar el tema, romper paradigmas y producir reflexión, y promover conocimientos específicos. El modelo propuesto fue capaz de instrumentalizar a los profesores en la identificación de los patrones del uso de drogas. Consideraciones finales: evaluación de especialistas en el área de la salud, se constituye como una etapa fundamental en la búsqueda por mayor éxito en la oferta de capacitaciones de esta naturaleza. Los materiales destinados a la capacitación de profesores, además del aspecto técnico, deben preceder por la diversidad contextual de actuación docente.

Descriptores: Capacitación en Servicio; Educación; Investigación Cualitativa; Profesores; Servicios de Salud Escolar.

INTRODUÇÃO
0 reconhecimento

da

necessidade de se discutir o uso de substâncias psicoativas (SPA) no contexto escolar é algo que vem florescendo na 
sociedade brasileira e no contexto político desde a década de 1980 , por se tratar de um aspecto da realidade de jovens e adolescentes. Assuntos como esse, que fazem interface entre educação e saúde, exigem processos formativos e políticos para que haja a implementação de ações concretas. Apesar disso, no Brasil, os programas voltados ao tema, em sua grande maioria, não possuem diretrizes claras para sua articulação com os projetos político-pedagógicos escolares. Ademais, há relutância por parte dos professores em abordar o uso de álcool e outras drogas no trabalho, por ausência de formação adequada ou mesmo de interesse $\mathrm{e}^{1-3}$.

Outros fatores, como as representações sociais (forma como as pessoas interpretam 0 cotidiano), atitudes e percepções dos professores sobre à adolescência e uso do álcool e outras drogas nesta fase, frequentemente tem se mostrado negativas, estigmatizadas e pautadas em conceitos do senso comum ${ }^{4,2}$. Apesar disso, os educadores reconhecem a escola como espaço privilegiado para implementação de ações voltadas à prevenção do uso de substâncias psicoativas, e têm trabalhado o tema, dentro de suas possibilidades, através de pesquisas, debates, palestras e atividades lúdicas ${ }^{5}$, o que sinaliza que investir em estratégias mais inovadoras de capacitação para este público talvez possa motivar outras ações dessa natureza.

Neste contexto, 0 presente estudo, que é desdobramento de um predecessor, foi elaborado, visto que, os resultados iniciais indicaram que a ausência de capacitação docente é uma dificuldade comumente percebida em sua atuação, frente ao enfrentamento do consumo de drogas na escola e, que modelos de capacitação devem ser mais direcionados a atender demandas locais $^{5}$. Desta forma, elaborou-se uma proposta direcionada para a realidade de uma escola estadual de Ensino Fundamental e Médio do interior do Estado de São Paulo, Brasil. Para isso, pautou-se em Estratégias de rastreamento e Intervenções Breves, que são diretrizes internacionais para treinamento de pessoal em prevenção do uso de álcool e outras drogas. Dessa forma, foi delineado a seguinte questão de pesquisa: "como os especialistas da área de álcool e outras drogas avaliam o conteúdo desta temática, voltada à docentes da educação básica?"

Estudos prévios evidenciam que programas de prevenção para o uso de 
drogas nas escolas, necessitam da participação de profissionais especializados, visando um maior planejamento e execução multiprofissional, atrelados a redes de apoio e legislações vigentes ${ }^{2,5}$. Apesar disso, há escassez de publicações sobre avaliação por especialistas de materiais destinados ao treinamento e capacitação de profissionais em prevenção do uso de substâncias psicoativas em contextos específicos, como a escola, tema de interface entre educação e saúde. Estratégias de rastreamento e intervenções breves têm sido amplamente utilizadas em diversos países, no intuito de instrumentalizar as ações preventivas para o uso de álcool e outras drogas entre profissionais de saúde. Trata-se de uma ferramenta universal, que pode ser utilizada por profissionais de diversas áreas ${ }^{6}$, como a educação, porém, até o momento, não tem sido explorada neste âmbito.

Nesse sentido, partindo da percepção de professores, foi construído um material para capacitação em prevenção do uso de drogas no contexto escolar, buscando atender suas expectativas. Assim, o objetivo deste estudo foi elaborar uma capacitação sobre o uso de substâncias psicoativas destinada a professores de ensino médio e fundamental e submetê-lo à avaliação por especialistas.

\section{MÉTODO}

Pesquisa metodológica ${ }^{7,8}$, seguida por etapa qualitativa, descritiva e exploratória9 ${ }^{9}$, realizada no município de São Carlos, interior de São Paulo. Neste estudo, aferiu-se a concordância interavaliadores ou concordância entre juízes, que pode ser definida como uma medida de consistência que avalia o quanto dois ou mais avaliadores fornecem igual classificação para uma condição $^{8}$, que, no presente estudo, avaliou-se a capacitação por meio de um questionário de avaliação.

A partir da análise de um estudo que avaliou as percepções, dificuldades e ações de professores frente às drogas na escola ${ }^{5}$, foi elencado temas com melhor potencial para qualificar este público-alvo, nas lacunas identificadas, com enfoque nos conteúdos de fundamentação úteis para o planejamento de ações de prevenção no âmbito escolar, divididos em quatro aulas: (1) substâncias psicoativas mais utilizadas no Brasil; (2) fatores de risco e de proteção associados ao consumo de drogas; rastreamento do uso de álcool e outras drogas na escola, a partir do 
ASSIST (Alcohol, Smoking and Substance Involvement Screening Test ou Teste de Triagem do Envolvimento com Álcool, Tabaco e Outras Substâncias). 0 referido instrumento, é um teste que possibilita o rastreamento do uso de álcool e outras drogas, que tem se mostrado muito útil para a prática de prevenção na área de Saúde ${ }^{10}$; (3) aplicação de Intervenções Breves no contexto escolar; e (4) avaliação dos estágios de prontidão para mudança, encaminhamento e monitoramento das ações.

O desenvolvimento dos referidos temas, foram propostos no modelo de aulas expositivas dialogadas ministradas com uma carga horária total de 16 horas (considerando espaços de diálogo para integração do conteúdo teórico e vivência dos professores no cotidiano de seu trabalho) e fundamentou-se em: (I) adaptações de diretrizes internacionais para treinamento de pessoal em prevenção para o uso de álcool e outras drogas, a partir de intervenções consideradas efetivas ${ }^{6,11}$; (II) pesquisa bibliográfica, do tipo revisão narrativa, ou seja, não foram utilizados critérios explícitos e sistemáticos para busca na literatura científica, mas foi realizada uma atualização no tema para contribuir com o debate do assunto ${ }^{12}$. Para cada uma das aulas foram definidos objetivos, desenvolvimento e conclusão.

Com o objetivo de melhorar a capacitação quanto à clareza, aceitabilidade e confiança, após a construção de uma proposta preliminar, uma primeira versão do treinamento foi submetida a um comitê formado por três especialistas contatadas pela pesquisadora, selecionadas por conveniência em junho de 2016. Como critérios de inclusão neste comitê, estabeleceu-se: ser graduado em cursos da área de saúde; possuir pós-graduação strictu senso (mestrado ou doutorado), ter realizado pesquisas referente ao uso e abuso de substâncias psicoativas. Como critério de exclusão, definiu-se a não avaliação do treinamento na íntegra.

Foi realizado um primeiro contato com cinco especialistas, via email, questionando-os sobre a possibilidade de participação no estudo, explicando a finalidade da avaliação e como ela seria realizada. Três aceitaram e foi encaminhado outro e-mail, reiterando os objetivos, encaminhando o Termo de Consentimento Livre e Esclarecido (TCLE), as aulas da capacitação para análise (explicando a ideia proposta para a ministração das mesmas) e solicitando que cada especialista fizesse uma leitura 
avaliativa e fornecesse um parecer sobre o modelo do material apresentado, a partir de questionamentos sobre conteúdo e linguagem utilizada; objetivos propostos para cada aula; clareza e logicidade das informações; coerência frente às demandas apontadas pelos professores; potencial de geração de reflexão sobre o papel da escola e do educador frente à problemática do uso de drogas (com enfoque em ações preventivas); carga horária e viabilidade de aplicação no contexto da escola, bem como campos destinados a sugestões de alteração ou inclusão de temas nas aulas. Foi estabelecido um prazo médio de 20 dias para análise e devolução.

Embora tenha sido utilizado um questionário com questões fechadas, as entrevistadas receberam a oportunidade de responderem livremente e de forma independente $\mathrm{o}$ instrumento de coleta de informações, onde puderam pontuar formas diferentes de metodologias, evitando, neste sentido, inferências nos resultados.

Para isso, as aulas foram enviadas em formato PowerPoint. Cada aula possuía um slide explicativo sobre seu objetivo. A princípio, foi explicado às especialistas que o principal intuito seria o de estimular os professores à participação, através de discussões sobre os temas abordados, tornando as aulas mais dinâmicas.

No que se refere à análise qualitativa, os dados foram inseridos no Software Atlas ti versão 5.2, visando sua organização e gerenciamento. Para a análise dos dados, foi utilizada a Proposta Operativa de Minayo ${ }^{13}$, que consistiu nas seguintes etapas: a) Ordenação dos dados: após a organização dos relatos, foi realizada uma leitura primária de todo o material, possibilitando às pesquisadoras um panorama horizontal dos achados em campo; b) Classificação dos dados: após a primeira etapa, foi efetuada a leitura exaustiva e repetida dos textos, a chamada "leitura flutuante", visando apreender as estruturas de relevância e as ideias centrais que as especialistas tentaram transmitir. 0 próximo passo consistiu na leitura transversal de cada corpo, recortando cada documento, visando a produção de unidades de sentido, que funcionaram como gavetas ou microtemas. Posteriormente, as unidades de registro foram processualmente alocadas e agrupadas em categorias mais amplas ou temas, buscando-se construir um sistema de análise; c) Análise final ou síntese interpretativa: foi realizada a articulação dos dados empíricos com o 
referencial teórico e os achados da literatura científica sobre o tema (álcool e outras drogas no ambiente escolar), com vistas à construção da síntese analítica final.

Destaca-se que a análise qualitativa foi efetuada de forma independente por duas pesquisadoras, com posterior comparação e discussão das análises. Os relatos das especialistas participantes foram identificados pela letra "E" (E1, E2 e E3).

Em relação à avaliação de concordância interavaliadores, foi analisada a porcentagem de concordância das respostas fornecidas pelas especialistas, para cada uma das questões propostas. Trata-se de uma medida simples, aferida pela divisão do número de respostas comuns e número de respostas totais ${ }^{14}$.

A pesquisa foi aprovada por Comitê de Ética em Pesquisa em Seres Humanos da Universidade Federal de São Carlos, por meio do parecer $n^{\circ} 716.596$, sendo respeitados os aspectos éticos contidos na Resolução no 466/2012 do Conselho Nacional de Saúde do Brasil.

\section{RESULTADOS E DISCUSSÃO}

As três especialistas participantes são do sexo feminino, sendo uma psicóloga e uma enfermeira, ambas doutoras, com mais de cinco anos de experiência em ensino no nível superior e treinamento de pessoas na área de prevenção ao uso de substâncias psicoativas. A terceira é enfermeira, mestra, com experiência de dois anos em ensino superior. A média de idade encontrada foi de 40 anos.

Foram avaliados 11 itens direcionados aos diferentes aspectos da capacitação dos professores sobre a temática proposta (como mostra o Quadro 1). Apenas dois itens não apresentaram concordância entre as especialistas: carga horária sugerida inicialmente, que foi de 16 horas, e adequação do conteúdo às demandas dos professores.

Mediante avaliação das especialistas, a carga horária total da capacitação foi reestruturada para 12 horas, visando uma previsão de duração máxima por aula de três horas. Condensar o conteúdo foi sugerido como forma de facilitar a participação dos docentes na capacitação. Sabe-se que, para abordar a temática de drogas no ambiente escolar, o fator "tempo" é fundamental, pois além de viabilizar a formação, a implementação de ações também depende de sua disponibilidade ${ }^{1}$. 
Em relação à adequação do conteúdo às demandas, que foi uma variável investigada, visando minimizar as lacunas de conhecimento dos educadores, Brener et $\mathrm{al}^{15}$, relatam que os responsáveis por essas ações, necessitam de atualização no tema e estratégias de ensino, visando aumentar a confiança desses profissionais, incentivando discussões de novas possibilidades com colegas, ampliando o rol de possibilidades de atuação na área de educação em saúde, objetivando a eficácia e reduzindo comportamentos de risco entre os alunos ${ }^{15}$.

Quadro 1 - Itens de avaliação de concordância interavaliadores. Junho de 2016. São Carlos, SP, Brasil. Questão Resposta Concordância

1. O conteúdo e a Sim $100 \%$ estratégia de ensino estão adequado ao público-alvo ao qual se destina?

2. Os objetivos de cada aula são alcançados?

3. A carga horária sugerida está adequada à realidade da escola?

4. A linguagem utilizada está adequada ao público-alvo?

5. 0 conteúdo discutido contempla as necessidades $\mathrm{e}$ demandas dos professores?

6. Há possibilidade de se executar o conteúdo proposto no contexto escolar?
Não $\quad 66,6 \%$

Sim

$100 \%$

Sim

$66,6 \%$

$\operatorname{Sim}$

$100 \%$

\begin{tabular}{|c|c|c|c|}
\hline & $\begin{array}{l}\text { As aulas estão } \\
\text { organizadas } \\
\text { numa sequência } \\
\text { lógica? }\end{array}$ & Sim & $100 \%$ \\
\hline 8. & $\begin{array}{l}\text { Clareza quanto à } \\
\text { proposta do } \\
\text { treinamento? }\end{array}$ & Sim & $100 \%$ \\
\hline 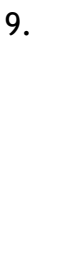 & $\begin{array}{l}\text { O treinamento } \\
\text { auxilia, de } \\
\text { alguma forma, na } \\
\text { implementação } \\
\text { de ações de } \\
\text { prevenção no } \\
\text { âmbito escolar? }\end{array}$ & Sim & $100 \%$ \\
\hline . & $\begin{array}{l}\text { O treinamento, } \\
\text { da forma como } \\
\text { foi elaborado, } \\
\text { possibilita } \\
\text { refletir sobre o } \\
\text { papel da escola } \\
\text { frente à } \\
\text { problemática do } \\
\text { uso de álcool e } \\
\text { outras drogas? }\end{array}$ & Sim & $100 \%$ \\
\hline 11. & $\begin{array}{l}\text { O treinamento, } \\
\text { da forma como } \\
\text { foi elaborado, } \\
\text { possibilita uma } \\
\text { reflexão sobre o } \\
\text { papel do } \\
\text { professor frente } \\
\text { à problemática } \\
\text { do uso de álcool } \\
\text { e outras drogas, } \\
\text { em seu contexto } \\
\text { laboral? }\end{array}$ & Sim & $100 \%$ \\
\hline
\end{tabular}

Foram produzidas quatro categorias temáticas: (1) Construir estratégias em parceria;

Contextualizar o tema; (3) Quebrar paradigmas e produzir reflexão; e (4) promover conhecimentos específicos.

Para além da necessidade de adquirir conhecimento teórico-prático sobre o consumo de drogas entre adolescentes, por meio de um movimento educativo conteudista e transversal, isto é, o especialista transmitindo informação aos ouvintes, as 
entrevistadas relataram, a partir de suas experiências, que os docentes necessitam, inicialmente, serem ouvidos. Apenas a partir da escuta e da reflexão sobre as vivências dos docentes no espaço escolar, é que estratégias de formação sobre o tema poderão ser construídas, de forma a fornecer sentido ao público e serem incorporadas no cotidiano de trabalho. Este achado vai ao encontro de um estudo prévio que discute que a oferta de formação sobre o tema não é garantia de uma prática efetiva e, é preciso considerar as opiniões dos educadores sobre o assunto, ainda que traspassadas por um viés moral $^{16}$.

Penso que a capacitação tende a ser mais efetiva se o conteúdo programático for mais sucinto. Isso ajudaria a abrir um espaço para o professor fazer o relato de suas experiências sobre como é o seu diaa-dia e o dia-a-dia da escola no enfrentamento da problemática das drogas $[\ldots]$. (E2)

Também penso em uma forma de motivar e incentivar a participação de professores: criar espaços para troca de experiências entre professores e ministrantes do conteúdo, visando amplificar uma discussão sobre o assunto. (E2)

Estudos científicos indicam que uma intervenção relativa ao tema de uso e abuso de álcool e outras drogas, apresenta maior probabilidade de ser efetiva, se esta for fundamentada na Journal Health NPEPS. 2019 jan-jun; 4(1):182-199. experiência e na opinião do público junto ao qual se pretende trabalhar. Isto é, a proximidade com o contexto laboral e com as reais demandas dos educadores tende a aumentar sua adesão a ações desta natureza e, também, a provocar mudanças nas atitudes e nas percepções a respeito do assunto ${ }^{4,16,17-19}$.

Num contrassenso, embora os próprios professores e especialistas que trabalham com a problemática do uso de SPA concordem que a escola se constitua em um ambiente privilegiado para abordar o tema, os modelos de ação, especialmente os de prevenção direcionados a temas transversais, são tradicionais, verticais e em alguns casos, calcados em discurso moral e de amedrontamento, ao passo que, deveriam ser tratados de forma transformadora e integrada à realidade ${ }^{4,20,21}$.

Acho que vocês poderiam enfatizar mais o papel do professor, forma de sensibilizá-lo e trazê-lo para refletir mais antes de dar as respostas. (E1)

As entrevistadas também destacaram que a busca pela participação ativa dos professores na construção das estratégias de formação sobre álcool e outras drogas tende $\mathrm{a}$, de fato, sensibilizá-los e motivá-los para o tema; caso contrário, as atividades 
educativas pontuais representarão apenas mais um trabalho a ser realizado ou mera sobrecarga laboral.

Por conseguinte, o planejamento de intervenções junto aos professores, deve transcender a mera transmissão de informações sobre os diferentes tipos de drogas e os prejuízos associados ao seu consumo, de modo que, a prática de ações pontuais junto aos alunos usuários ou suspeitos de serem, deem lugar a outras ações de promoção de saúde contínuas, integradas ao cronograma de atividades da instituição e legitimadas, de fato, em sua proposta pedagógica ${ }^{3,21}$. Além disso, a literatura evidencia que o uso de técnicas de ensino inovadoras aumenta a chance de a escola desenvolver um programa voltado à prevenção ao uso de drogas ${ }^{22}$.

Outro aspecto crucial para a realização da proposta de formação de professores sobre o tema, é a escolha do tempo e do espaço para que as estratégias sejam realmente efetivadas, devendo ser pensada com cuidado e definidas a partir do diálogo com os próprios educadores, visando estabelecer parcerias viáveis.

Por experiência pessoal prévia, os professores não se motivam a participar de outras atividades que já não estejam previstas em sua rotina habitual de trabalho. (E2)
O ideal é verificar a disponibilidade de tempo junto aos professores de cada unidade escolar. (E3)

[...] depende muito da disponibilidade da direção da escola, não apenas em ceder o espaço, mas promover aceitação $e$ engajamento dos professores. (E1)

A partir dos relatos, verifica-se a importância de ajustar as ações de prevenção à disponibilidade dos educadores, consultando e optando por um local de fácil acesso, de preferência na própria escola, em horários que não extrapolem a carga horária laboral, porém, respeitando-se um espaço de privacidade e sigilo, para que eles tenham liberdade de expressão na discussão sobre o tema.

Para tanto, o apoio da gestão escolar torna-se fundamental, sendo necessário o diálogo prévio para a definição das estratégias de formação, tanto em termos de conteúdo quanto de organização geral. Um resultado interessante mostrou que quanto mais experiência tem um dirigente na educação, maior a chance de se implementar um programa para prevenção do uso de substâncias em sua escola, provavelmente devido à melhor noção da realidade que vivenciam seus estudantes ${ }^{22}$.

\section{Contextualizar o tema}


As entrevistadas apontaram a importância de se criar uma rede de conhecimentos e reflexão sobre 0 cenário ou contexto no qual a temática álcool e outras drogas se manifesta. Para isto, elas sinalizaram como essencial que a discussão sobre o papel da instituição escolar na sociedade contemporânea anteceda o desenvolvimento de ações mais específicas, como a problematização da questão do uso de SPA entre adolescentes, por exemplo.

Inserir mais perguntas para que os professores reflitam sobre o tema, tipo: a escola no século XXI é a mesma do século XX ou XIX? Por que vocês acham que os adolescentes usam drogas? (E1)

Ronzani e Silveira ${ }^{3}$ salientam que é imprescindível refletir sobre assuntos fundamentais voltados a educação, destacando a importância de se conectar o ensino especializado com o ensino voltado ao desenvolvimento dos potenciais dos indivíduos.

Para a elaboração de estratégias de formação de professores sobre o tema álcool e outras drogas, outro aspecto destacado consistiu na necessidade de se promover informações sobre as peculiaridades do adolescente em seus aspectos biológicos e psicossociais, construindo-se ferramentas objetivas e subjetivas por meio das quais os Journal Health NPEPS. 2019 jan-jun; 4(1):182-199. docentes possam, de forma contextualizada e reflexiva, destinar suas ações em sala de aula, gerando espaços de livre diálogo com os educandos sobre a temática.

Acho que deveria iniciar pelas características psicossociais $e$ biológicas do adolescente e depois apontar ou descrever a função do professor nesse contexto; porque alguns professores não têm conhecimento das dificuldades que os adolescentes enfrentam hoje. (E1)

A literatura indica que é essencial conhecer o aluno com o qual se trabalha, isto é, compreender além de seus hábitos, peculiaridades e possibilidades, o contexto em que vive e como se dão suas relações com a família, com grupos de pares e com a escola ${ }^{3}$.

As avaliadoras também referiram que, a partir deste movimento de contextualização e reflexão, os professores poderão melhor compreender o papel da escola na vida do adolescente, gerando uma relação mais autêntica entre educando e educador, o que, de fato, irá propiciar ações de diálogo e transformação.

Acho que tem que trazer mais reflexões sobre o papel da escola sobre $o$ desenvolvimento do adolescente. $A$ importância da escola para o adolescente e sua identidade. (E1) 
Quebrar paradigmas e produzir reflexão

A necessidade da superação de crenças estigmatizantes sobre o tema álcool e outras drogas, também foi referida como fator relevante de discussão coletiva no processo de formação de professores. As especialistas destacaram que, embora o tema perpasse o cotidiano escolar, muitas vezes mantem-se velado ou negado, bloqueando a possibilidade de superação de problemas ou situações reais enfrentadas pelos educandos, educadores e a escola como um todo.

[...] Professores precisam de formação, capacitação para um tema para o qual são diariamente solicitados, no caso, o uso e abuso de álcool e outras drogas, que ficam como um assunto 'velado' no dia-adia. Acredito que o conteúdo do treinamento tenha potencial para sensibilizá-los e capacitá-los. (E1)

A capacitação pode mudar crenças, conceitos errôneos e atitudes que os professores possam ter sobre os escolares que façam uso de substâncias. Perceber que podem fazer a diferença trazendo informações que possam despertar dúvidas sobre o uso de substâncias entre os jovens. (E3)

Trazer à tona um tema velado, comumente associado à ilegalidade ou à criminalidade e que gera medo e insegurança no espaço escolar, representa, de fato, um grande desafio para o professor, sendo a quebra de preconceitos o principal caminho para que os primeiros passos em direção ao desenvolvimento de ações emancipadoras sejam dados. Outrossim, cabe salientar o quão é necessário recusar a concepção de que o consumo de substâncias psicoativas é, sempre e invariavelmente, um comportamento desviante (patologia) ${ }^{23}$.

Neste movimento de superação de estigmas, que é um processo contínuo e reflexivo, as entrevistadas destacaram a importância do constante questionamento e da retomada consciente do papel do professor perante a problemática, corroborando com Ronzani e Silveira ${ }^{3}$ que, em sua pesquisa, destaca a necessidade de o professor autorreconhecer-se como agente formador que lida, cotidianamente, com a questão do uso de SPA, seja em sala de aula ou no entorno escolar.

Lançar a pergunta: o papel de trabalhar a prevenção do uso de substancias psicoativa é do professor? Por quê? (E3)

Enfatizar mais detalhadamente a importância do professor na vida do adolescente como forma de sensibilizá-lo e se comprometer na prevenção do uso de drogas. (E1)

Quanto a este aspecto, os mesmos autores realizam uma reflexão 
importante a respeito da função do educador, concluindo que o desempenho do papel formador não se equivale, necessariamente, a um acréscimo às atribuições da docência; é, senão, inerente a ela ${ }^{3}$.

Por fim, as entrevistadas também referiram a necessidade de inclusão de educandos/adolescentes no espaço de formação de professores sobre o tema, possibilitando a escuta daqueles que, rotineiramente, deparam-se com a problemática do uso de drogas. Deste modo, o assunto pode ser tratado de forma realística, criando-se possibilidades de diálogo aberto sobre 0 problema, que raramente é discutido no espaço escolar.

\section{[...] seria interessante descrever para os professores uma abordagem na qual eles incluiriam a participação de adolescentes neste processo, pois acho importante eles serem ouvidos. (E1)}

De acordo com Bezerra e Vieira ${ }^{24}$ ouvir os estudantes possibilita 0 conhecimento daquilo que denominam como "lado negligenciado", ou seja, fatores que podem levar e/ou estar associados ao consumo de SPA. Proceder a uma escuta qualificada dos mesmos poderá subsidiar a atuação mais efetiva dos educadores perante a problemática.

\section{Promover conhecimentos específicos}

Além da escuta, reflexão e superação de paradigmas, as especialistas também destacaram a necessidade de o professor obter conhecimento teórico-prático específico sobre a questão das drogas, fator crucial para que a escola tenha mais clareza sobre o problema.

Segundo elas, os temas podem envolver a descrição de aspectos epidemiológicos sobre drogas, a classificação das substâncias psicoativas, suas características e efeitos, bem como as estratégias e intervenções, especialmente em relação à prevenção.

Quanto mais instrumentalizados estiverem os trabalhadores do ambiente escolar, melhor serão suas atitudes em relação à problemática do uso de álcool e outras drogas. Quanto mais sensibilizados, maiores as chances de se implementar ações preventivas no contexto escolar, mesmo que sejam simples rodas de conversa, que abordem o tema direta ou indiretamente. (E2)

Com o conhecimento oferecido os professores têm condição de identificar com mais clareza os fatores de risco e de proteção e assim desenvolver ações preventivas $e$, se necessário, o encaminhamento para acompanhamento específico. (E3)

(A capacitação) deve estar clara $e$ direcionada para demonstrar as características de uso de drogas na população-alvo (adolescentes). (E1) 
Há clareza sobre o propósito de fazer o profissional de educação entender sobre os aspectos gerais de epidemiologia e classificação quanto aos efeitos farmacológicos das drogas, bem como rastrear $e$ intervir em situações de uso ou abuso de substâncias psicoativas, que retrata uma vivência cotidiana do professor em sala de aula nos dias atuais. (E2)

As propostas de capacitação docente precisam ser amplas, permanentes e continuadas, para que esses profissionais se tornem verdadeiramente envolvidos em práticas voltadas a prevenção e promoção de saúde ${ }^{25}$.

O conteúdo das aulas deve estar casado com os objetivos em questão. Porém, é necessário fomentar a discussão entre os professores para a realidade dos seus escolares. (E3)

Neste processo de suporte teórico aos professores sobre o tema, as entrevistadas destacaram a importância de a todo o momento, articular 0 conhecimento produzido às experiências vivenciadas no espaço escolar, buscandose unir teoria e realidade, o particular e o geral, em um movimento dialético e crítico que vise uma formação significativa. A junção entre saúde e educação pode incluir ganhos importantes voltados à formação de profissionais $^{26}$. Assim, os educadores estarão não só dotados de conhecimento Journal Health NPEPS. 2019 jan-jun; 4(1):182-199. sobre o assunto, mas também sensibilizados e motivados a desenvolverem ações junto aos educandos.

\section{CONSIDERAÇÕES FINAIS}

Diante da avaliação das especialistas, voltada à concordância para cada um dos itens submetidos ao julgamento, verificou-se que, com exceção das questões referentes a carga horária sugerida e à adequação do conteúdo às demandas dos professores, os demais temas obtiveram nível máximo de concordância, evidenciando que, as aulas construídas, preliminarmente, atendem aos objetivos da capacitação proposta.

Já a análise qualitativa possibilitou a discussão de aspectos importantes a serem considerados no processo de construção de uma capacitação, com efetiva abordagem sobre o uso e abuso de substâncias psicoativas destinado a professores de Ensino Médio e Fundamental.

Um dos aspectos refere-se à participação democrática de docentes, alunos e gestores escolares neste processo, algo que, segundo as especialistas, tende a possibilitar maior adesão dos professores a propostas de 
ações preventivas quanto ao uso/abuso de álcool e outras drogas, bem como a promover mudanças de atitudes e paradigmas quanto a um tema ainda permeado pelo viés moral e punitivo.

Como uma etapa anterior à discussão sobre a implementação de intervenções preventivas, as entrevistadas apontaram a necessidade de se discutir a função da escola na contemporaneidade e qual o perfil do aluno/adolescente que a frequenta. Cabe ponderar que alguns professores trazem consigo o seu referencial de adolescente, algo que tende a dificultar a construção de uma relação de empatia com os educandos. Da mesma forma, estão permeados pelo seu referencial de escola, que, a depender de suas perspectivas, pode impossibilitar a criação de uma relação dialógica e participativa com os escolares.

Neste sentido, reitera-se que, no processo de suporte teórico aos educadores sobre 0 tema, faz-se necessário articular o conhecimento produzido às experiências vivenciadas no espaço escolar, buscando-se unir teoria e realidade, o singular e o geral, em um movimento dialético e crítico que vise uma formação significativa e, também, a possibilidade de se construir de um espaço de transformação e de emancipação.

Diante do aporte teóricometodológico sistematizado a partir da avaliação de especialistas na área, conclui-se que a consulta a estes profissionais é uma etapa fundamental na busca por maior sucesso na oferta de capacitações desta natureza, bem como para que haja maior possibilidade de que as ações preventivas ao uso de drogas sejam sustentáveis, após a conclusão de treinamentos e capacitações.

\section{REFERÊNCIAS}

1. Adade M, Monteiro S. Educação sobre drogas: uma proposta orientada pela redução de danos. Educ Pesqui. 2014; 40(1): 215-230.

2. Ferreira TCD, Sanchez ZM, Ribeiro LA, Oliveira LG, Nappo SA. Percepções e atitudes de professores de escolas públicas e privadas perante o tema drogas. Interface (Botucatu). 2010; 14(34): 551-562.

3. Ronzani TM, Silveira PS. Prevenção ao uso de álcool e outras drogas no contexto escolar. Juiz de Fora: Ed. UFJF; 2014.

4. Araldi JC, Njaine K, Oliveira MC, Ghizon AC. Representações sociais de professores sobre o uso abusivo de álcool e outras drogas na 
adolescência: repercussões nas ações de prevenção na escola. Interface (Botucatu). 2012; 16(40): 135-46.

5. Silva PMC, Galon T, Zerbetto SR, Moura AAM, Volpato RJ, Gonçalves AMS. Percepções, dificuldades e ações de professores frente às drogas na escola. Educ Pesqui. 2018; 44: e182015.

6. Babor TF, Del Boca F, Bray JW. Screening, Brief Intervention and Referral to Treatment: implications of SAMHSA's SBIRT initiative for substance abuse policy and practice. Addiction. 2017; 112(Suppl 2): 110-117.

7. Melo WS, Oliveira PJF, Monteiro FPM, Santos FCA, Silva MJN, Calderon CJ, et al. Guide of attributes of the nurse's political competence: a methodological study. Rev Bras Enferm. 2017; 70(3):526-534.

8. Graham M, Milanowski A, Miller J. Measuring and Promoting Inter-Rater Agreement of Teacher and Principal Performance Ratings. Center for Educator Compensation Reform. [Internet] 2012 [cited 2018 Jan 24] Available from: https: / / files.eric.ed.gov/fulltext/ED 532068.pdf
9. Sampieri RH, Collado CF, Lucio MPB. Metodologia de Pesquisa. 5a ed. Porto Alegre: Penso; 2013.

10. Gonçalves AMS, Ferreira PS, Abreu AMM, Pillon SC, Jezus SV. Estratégias de rastreamento e intervenções breves como possibilidades para a prática preventiva do enfermeiro. Rev eletrônica enferm. 2011; 13(2): 355- 60.

11. Dimeff LA, Baer JS, Kivlahan, DR, Marlatt GA. Alcoolismo entre estudantes universitários: uma abordagem de redução de danos (BASICS). 1a ed. São Paulo: Fundação Editora da UNESP (FEU); 2002.

12. Costa PHA, Mota DCB, Paiva FS, Ronzani TM. Desatando a trama das redes assistenciais sobre drogas: uma revisão narrativa da literatura. Ciênc saúde coletiva. 2015; 20(2): 395406.

13. Minayo MCS. 0 desafio do conhecimento: pesquisa qualitativa em saúde. $14^{\text {a }}$ ed. São Paulo: Hucitec; 2014.

14. Alexandre NMC, Coluci MZO. Validade de conteúdo nos processos de construção e adaptação de instrumentos de medidas. Ciênc saúde coletiva. 2011; 16(7): 30613068. 
15. Brener ND, McManus T, Wechler H, Kann L. Trends in Professional Development for and Collaboration by Health Education Teachers-41 States, 2000-2010. J Sch Health. 2013; 83(10): 734-742.

16. Amato TC, et al. A atuação da educação na rede de atenção aos usuários de álcool e outras drogas. In Ronzani TM, et al. Redes de atenção aos usuários de drogas: políticas e práticas. São Paulo: Cortez; 2015.

17. Gosin MN, Dustman PA, Drapeau AE, Harthun ML. Participatory action research: creating an effective prevention curriculum for adolescents in the Southwestern US. Health Educ Res. 2003; 18(3): 363379.

18. Ronzani TM, Formigoni MLOS. Estratégias de rastreamento e intervenção breve ao uso de álcool na APS: um pouco de realidade. In: LUIS, M.A.V. (org.). Os novos velhos desafios da saúde mental. 1a ed. Ribeirão Preto: EERP/USP; 2008.

19. Wagner EF, Tubman JG, Gil AG. Implementing school-based substance abuse interventions: methodological dilemmas and recommended solutions. Addiction. 2004; 99(suppl. 2):106-119.
20. Dalbosco C, Pereira ALD. Proposta Pedagógica. In: Brasil. Ministério da Educação. Prevenção ao uso de drogas: a escola na rede de cuidados, Brasília, 2013 [cited 2016 Jan 20]; p. 4-9. Available from: http://abramd.org/wpcontent/uploads/2014/05/2013_SAL TO_PARA_O_FUTURO_Prevencao_ao_ uso_de_Drogas.pdf

21. Fonseca MS. Como prevenir o abuso de drogas nas escolas? Psicol Esc Educ Campinas. 2006; 10(2):339-341.

22. Pereira APD, Paes AT, Sanchez ZM. Fatores associados à implantação de programas de prevenção ao uso de drogas nas escolas. Rev Saúde Pública. 2016; 50: 44.

23. Sodelli M. A abordagem proibicionista em desconstrução: compreensão fenomenológica existencial do uso de drogas. Ciênc saúde coletiva. 2010; 15(3):637-644.

24. Bezerra AAC, Vieira EF. Quadro teórico. In: O enigma das drogas: faceta da diversidade que desafia pais e professores reconstruída a partir de memórias de adolescentes usuários de drogas. 1a ed. Curitiba: Appris; 2013.

25. Souza FB, Andrade ALM, Rodrigues TP, Nascimento MO, De Micheli D. Avaliação das concepções de 
educadores de escolas públicas e particulares sobre uso de drogas: um estudo exploratório. Estud pesqui psicol. 2015; 15(3):1081-1095.

26. Moreira A, Vóvio CL, De Micheli D. Prevenção ao consumo abusivo de drogas na escola: desafios $e$ possibilidades para a atuação do educador. Educ Pesqui. 2015; 41(1):119-135.

Conflito de interesses: Os autores declaram não haver conflito de interesses.

\section{Participação dos autores:}

- Concepção: Silva PMC, Galon T, Moura AAM, Volpato RJ, Zerbetto SR, Gonçalves AMS.

- Desenvolvimento: Silva PMC, Galon T, Moura AAM, Volpato RJ, Zerbetto SR, Gonçalves AMS.

- Redação e revisão: Silva PMC, Galon T, Moura AAM, Volpato RJ, Zerbetto SR, Gonçalves AMS.

Como citar este artigo: Silva PMC, Galon T, Moura AAM, Volpato RJ, Zerbetto SR, Gonçalves AMS. Capacitação multiprofissional sobre drogas no contexto escolar: formação, saúde e educação. J Health NPEPS. 2019; 4(1):182-199. 